\title{
Material and technological investigation of machined surfaces of the OCHN3MFA steel
}

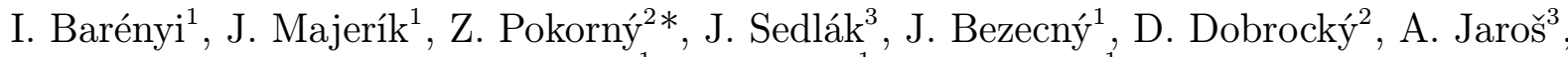 \\ M. Eckert ${ }^{1}$, J. Jambor ${ }^{1}$, R. Kusenda ${ }^{1}$ \\ ${ }^{1}$ Department of Engineering, Alexander Dubcek University of Trencin, Trencin, Slovak Republic \\ ${ }^{2}$ Department of Mechanical Engineering, the University of Defence in Brno, Brno, Czech Republic \\ ${ }^{3}$ Department of Manufacturing Technology, Brno University of Technology, Brno, Czech Republic
}

Received 10 October 2018, received in revised form 21 February 2019, accepted 21 February 2019

\begin{abstract}
This paper deals with the effect of selected cutting parameter values in machining of OCHN3MFA steel on AFM and SEM microstructural analysis, cutting forces, nanohardness, $2 \mathrm{D}$ and $3 \mathrm{D}$ surface roughness, and material removal rate of surface layers after machining. OCHN3MFA steel was selected and used to perform experiments. Firstly, the selected steel was investigated before machining tests, due to the checking of the initial microstructure and chemical composition. The microstructure was performed on the Tescan Vega TS 5135 scanning electron microscope (SEM) with the X-ray microanalyzer Noran Six/300, and the Oxford Instruments MFP-3D Infinity atomic force microscope (AFM). Chemical composition was analyzed on Tasman Q4 surface analyzer. All machining tests of the used samples were performed under the selected cutting parameters in the SU 50A lathe machine tool with the CNMG 120408-M5 cementite carbide cutting insert clamped in the suitable DCLNR 2525M12-M cutting tool holder. During the machining process of testing samples, individual components of cutting forces were measured on a Kistler 9257B piezoelectric dynamometer with their subsequent evaluation using software Dynoware. Other experiments following the machining process were performed, evaluating the effect of selected cutting parameters on surface hardening. Surface hardening after machining of testing samples was subsequently measured on Hysitron TI950 Triboindenter with a Cube Corner measuring tip and evaluated by software Triboscan. 2D and 3D surface roughness and material removal rate (MRR) were finally performed on Talysurf CCI Lite and evaluated by software TalyMap Platinum.
\end{abstract}

Key words: mechanical properties, microstructural analysis, cutting forces, nanoindentation, surface roughness

\section{Introduction}

At present, efforts to increase efficiency and productivity of production along with increasing product quality in all industries may be witnessed. This is precisely the result of the progress in the design of the machine and cutting tools we are continually introducing with still more modern, more powerful and precise machines and cutting tools, enabling us to apply high cutting conditions and work with high precision and productivity.

With regard to the trend in quality improvement of the manufactured components, it is necessary to ask whether the higher cutting conditions applied during machining do not affect the properties of the machined surface. Experiments and practice-based findings show their influence in a significant way. It is essential not only to monitor the microgeometry of machined surfaces but also to change the structure and properties within the surface layer of the workpiece. These changes caused by the deformation and temperature processes during the machining process can have a very negative effect on the functional operation of components.

It has been statistically proven that the beginning of damage to many components during technical op-

*Corresponding author: e-mail address: zdenek.pokorny@unob.cz 
Table 1. The chemical composition of examined OCHN3MFA steel

\begin{tabular}{lccccccc}
\hline & $\mathrm{C}$ & $\mathrm{Mn}$ & $\mathrm{Si}$ & $\mathrm{Cr}$ & $\mathrm{Ni}$ & $\mathrm{Mo}$ & $\mathrm{V}$ \\
\hline Min & 0.33 & 0.25 & 0.17 & 1.20 & 3.00 & 0.35 & 0.10 \\
Max & 0.40 & 0.50 & 0.37 & 1.50 & 3.50 & 0.45 & 0.80 \\
Spectral analysis & 0.41 & 0.55 & 0.38 & 0.92 & 2.85 & 0.22 & 0.13 \\
\hline
\end{tabular}

eration occurs mostly on the surface or just below it. This knowledge demonstrates the need to monitor the state of the surface layer and to control its properties, particularly in cases where high-stress components along with high operating life and reliability are required.

The achieved results of the research published in the authors' articles [1-3] as well as the knowledge obtained from industrial practice show the need to evaluate the surface conditions of these parts as the result of a particular technological process depending on specific operating conditions of the surface in operation. It is precisely this view of surface assessment that is often referred to as surface integrity. According to the authors $[4,5]$, the concept of surface integrity can be defined as the sum of the conditions under which the functional surface is formed, taking into account the consequences of the technological methods manifested on the quality of the machined surface of the manufactured components. Quality of components can generally be measured by dimensional and shape accuracy, the texture of the surface, and properties of the surface layer $[6,7]$. As previously defined in the authors' research papers $[8,9]$, the most frequently evaluated surface integrity parameters include microgeometry (surface texture), hardening of the surface layer after machining, as well as structural changes in the surface layer. When investigating the properties of machined surfaces, it is necessary to start with the production technology itself. Hence, it is necessary to show the creation of a new surface, since the machining technology has the greatest influence on finishing the parts' surfaces, and therefore on the final surface condition. Each surface machining technology leaves special characteristics and creates a special surface condition. Therefore, the force effect of the cutting tool is deformed not only by the material leaving in the form of chips but also by the effect of a thin surface layer formation under the machined surface. For this reason, monitoring of the individual components of cutting forces was carried out during the process of test samples machining and their subsequent evaluation.

From the point of view of surface formation, it is also necessary to focus on the last phase of the chip formation process represented by fracture. The type and character of a fracture depend on the crystal structure of the machined material and the conditions of the plastic deformation mainly given by the cutting conditions [10]. Several factors influence chip formation. The main factor is the material of the workpiece and its mechanical properties. All of these factors have an impact on the formation of chips. Also, the cutting conditions directly affect the size and shape of the chips, with the feed rate having a more pronounced impact than the cutting speed [11, 12]. For this reason, the authors have chosen variable feed rate $f\left(\mathrm{~mm} \mathrm{rev}^{-1}\right)$, cutting speed $v_{\mathrm{c}}\left(\mathrm{m} \mathrm{min}^{-1}\right)$, and cutting depth $a_{\mathrm{p}}(\mathrm{mm})$ as the constant cutting parameters.

The research performed by the authors of the article joins a project entitled "Research of selected metallic structural materials subjected to extreme impact loads". The project focuses on material research with the application output in the area of mechanical engineering. The current global trend was characterized by increasing the requirements for allowable values of the stresses of the components under dynamic and impact loads.

Therefore, the task of selecting a material suitable for a particular application involving extreme impact loads requires a more detailed examination of the properties of these materials. Solving of material issues for specific applications is closely related to mechanical machining of the materials under investigation with available technologies. The major problem in this specialized area is the lack or the absence of relevant literature sources since most of the important data remain the subject of proprietary business information. Moreover, research performed by the authors of the article in this field adds an essential element by publishing recent knowledge from this field.

At present, a special steel production uses mainly

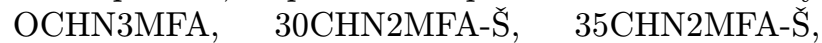
25CH17N2B-S, 30CHRA, 49KF, and 23CHGS2MFLU types of steel with a fairly defined content of impurities and alloying elements (C, Si, Mn, Cr, Mo, V, S, P, $\mathrm{Cu}$ ). The current trend in these semi-products is continuously improving their mechanical properties [13]. OCHN3MFA steel is middle alloyed steel containing nickel, chromium, molybdenum, and vanadium (see Table 1). This specific material is mostly used for the production of high-loaded machine parts, esp. high calibre barrels of weapon systems such as tanks, howitzers, and other army mobile vehicles. During the process of shooting the bore of the barrel is exposed to very high pressure, as well as temperature. Therefore, high tensile strength and hardness together with good 
Table 2. Mechanical properties of examined OCHN3MFA steel

\begin{tabular}{cccccc}
\hline Mechanical properties & $\begin{array}{c}\text { Tensile strength } \\
R_{\mathrm{m}}(\mathrm{MPa})\end{array}$ & $\begin{array}{c}\text { Limit of } \\
\text { proportionality } \\
R_{\mathrm{E}}(\mathrm{MPa})\end{array}$ & $\begin{array}{c}\text { Toughness } \\
K C U(\mathrm{~J}) \\
\text { at } 20^{\circ} \mathrm{C}\end{array}$ & $\begin{array}{c}\text { Hardness } \\
\mathrm{HV}\end{array}$ & $\begin{array}{c}\text { Elongation } A_{5} \\
(\%)\end{array}$ \\
\cline { 2 - 6 } & 1500 & 1079 & 23 & 500 & 20 \\
\hline
\end{tabular}

plastic properties are strictly required for these special applications. However, the manufacturing process for gun barrel also includes machining operations to finalize the product, and these operations get more complex with increasing values of the hardness of the processed material.

Steel was delivered in a quenched and hightempered state, where also electroslag or vacuum remelting are used to improve the microstructural purity and mechanical properties. There exist a number of equivalents to OCHN3MFA, for example, 34NiCrMoV14-5，35NiCrMoV12-5，33NiCrMoV15, $30 \mathrm{NiCrMoV} 14$, and AISI 4340. These types of steel can be included in this experimental work, especially for comparison purposes. Several foreign authors [1416] made their material and technological research on OCHN3MFA steel equivalents. For instance, AISI 4340 steel is widely used in industrial applications thanks to its toughness, high strength, and the ability to retain good fatigue strength at various temperatures [17], e.g. in fatigue critical components. Some of the authors $[13,18,19]$ have conducted their investigations on the AISI 4340 steel (as the equivalent of the OCHN3MFA), which is widely employed in automotive and aircraft industries, and in the manufacture of machine components, due to its advantageous combination of strength and toughness.

For this reason, this article focuses on the study of mechanical properties, cutting forces, and surface hardening of OCHN3MFA steel machined with specified cutting parameters, as well as their influence on surface topography (surface roughness) after machining. Experiments involve the evaluation of wear of tools after machining. Metallography techniques were evaluated using the SEM (Scanning Electron Microscopy) and the AFM (Atomic Force Microscopy) methods. Metallographic tests were performed on samples in surface layers before and after machining. Results after machining were also compared to the nanohardness measurement and surface roughness techniques.

\section{Experimental work}

\subsection{Material characterization}

The base material used for this paper is a middle alloyed OCHN3MFA steel used in the weapon indus- try. The raw material was cast as bars subsequently forged, heat treated and vacuum remelted. At first, the chemical composition of selected steel was verified. CCD-based Q4 TASMAN optical emission spectrometer was used to measure the chemical composition of selected steel (Table 1). Calibration was performed by Fe base under NSC4A standards (Table 1). Three different groups of samples were made of steel, each group with different machining parameters (see chapter 2.3.).

Mechanical properties of experimental materials were also verified. Vickers hardness measurement (HV5) of experimental samples was performed, using Instron-Wolpert testing device with loading $49.03 \mathrm{~N}$ and indentation time $t=10 \mathrm{~s}$ (EN IS0 6507-1). Standard tensile strength test (EN ISO 6892-1) was performed to acquire strength characteristics, while the standard Charpy impact test (EN ISO 179-1) was used to measure toughness. All mechanical properties acquired by these measurements of OCHN3MFA steel are summarized in Table 2.

\subsection{SEM and AFM microstructural analysis of bulk material and surface layers}

All samples used for metallographic observation were prepared through the standard metallographic sample preparation process. Samples were wet ground using silicon carbide paper with grit from 80 down to 2000 , subsequently polished, and finally etched using Nital $3 \%$ as the etchant. SEM Tescan Vega TS 5135 with X-ray microanalyzer Noran Six/300 were used to create images of the basic microstructure and surface layers after machining. The electro-microscopy method was used on the basis of electron properties of waves and is analogous to conventional optical microscopy. The place of the light source is an electron nozzle, and optical lenses are replaced by electromagnetic lenses (coils). The value of the theoretical resolution range using an electron beam is $10^{-11} \mathrm{~m}$.

AFM represents an uncommonly used method for investigating micro- and nanostructure of metallic materials. The principle of this microscope is to scan the sample surface with a very small tip, which has a tip-radius of only a few nanometers. In the material sciences, the most interesting modes are those that measure Young's modulus, indentation, hardness, or dissipation. Oxford Instruments MFP-3D Infinity AFM microscope with which measurements were per- 
Table 3. Setup cutting conditions

\begin{tabular}{lcc}
\hline Cutting condition & Constant/variable & Value \\
\hline Cutting speed & $v_{\mathrm{c}}\left(\mathrm{m} \mathrm{min}^{-1}\right)($ constant $)$ & 180 \\
Feed rate 1 (sample A1) & $f_{1}\left(\mathrm{~mm} \mathrm{rev}^{-1}\right)($ variable) & 0.22 \\
Feed rate 2 (sample A2) & $f_{2}\left(\mathrm{~mm} \mathrm{rev}^{-1}\right)($ variable $)$ & 0.34 \\
Feed rate 3 (sample A3) & $f_{3}\left(\mathrm{~mm} \mathrm{rev}^{-1}\right)($ variable) & 0.41 \\
Radial depth of cut & $a_{\mathrm{p}}(\mathrm{mm})($ constant) & 1 \\
\hline
\end{tabular}

formed allows for exploring material properties using AM-FM Viscoelastic Mapping Mode. AM-FM mode can register nanomechanical properties of materials across a wide range of Young's modulus (from less than $1 \mathrm{MPa}$ to hundreds of GPa), from biomaterials to metals and ceramics. AM-FM mode collects results by working at two cantilever resonances simultaneously. As the name suggests, the first resonance is used for tapping mode imaging, also known as amplitude modulation (AM), while the resonance mode works in frequency modulation (FM). In resonance, the cantilever frequency and phase respond sensitively to changes in sample properties. Higher frequency means greater stiffness or modulus. Indentation is yet another parameter describing the mechanical properties of the surface. Indentation represents the deformation of the surface when the tip is tapping on it.

\subsection{Machining process and parameters}

According to the specified cutting conditions (see in Table 3), CNMG 120408-M5 changeable cutting insert geometry with TP 0501 type of cemented carbide was used in machining tests. TP 0501 is a class of so-called Duratomic technology characterized by a high degree of resistance to high temperatures and wear. It is particularly suitable for some applications on steel and alloyed steels. Especially, it is also suitable for dry machining. Changeable cutting inserts of the class are coated with $\mathrm{Ti}(\mathrm{C}, \mathrm{N})+\mathrm{Al}_{2} \mathrm{O}_{3}$. The longitudinal turning of the samples, marked from A1 to A3, was carried out on SU 50A lathe machine with using BONDERITE L-MR 71-2 process liquid commonly used for turning, milling, and drilling operations. Setup cutting conditions $\left(v_{\mathrm{c}}, a_{\mathrm{p}}\right)$ were constant during machining tests; only the feed rate was variable (see Table 3).

Properly selected cutting conditions achieve the required quality of the machined surface, the smallest values of cutting forces, the optimum tool wear, tool life of the cutting tools, favourable chip shape, and high machining power $[4,8]$. Monitored parameters included force loading during longitudinal turning of OCHN3MFA steel, and surface roughness of machined surfaces, depending on the feed rate.

\subsection{Nano-hardness analysis of bulk material and surface layers after machining}

Nano-hardness measurement was performed on Hysitron TI-950 measuring device (directly from the company Bruker Ltd.) equipped with Triboscan software with $F=5000 \mu \mathrm{N}$ test load and $t=4 \mathrm{~s}$ holding duration. All nanoindentation tests were performed at room temperature with the application of Cube Corner geometry of indenter inside the CEDITEK Laboratory of Mechanical Testing in Trencin (Faculty of Special Technology). Nanoindentation tests were performed in cross-section measuring samples (see Fig. 2). Each nano-hardness value was determined as an average value, at least from three measurements. The depth of the hardened case was typically defined as the depth where the hardness reaches $50 \mathrm{HV}$ above core hardness in accordance with DIN 50190. Quasistatic nanoindentation tests involve pushing a diamond tipped indenter head into a material under either load or displacement control. Displacement $(h)$ is monitored as a function of the load $(P)$ throughout the load-unload cycle where resulting relation $P-h$ is known as the nanoindentation curve. The plastic part of deformation is typically used to determine Young's modulus, while the elastic-plastic part along with indent surface is used to evaluate hardness. The area bounded by both loading and unloading curves is equivalent to dissipation energy. During all performed nanoindentation tests, load together with displacement were recorded, while Cube Corner indenter was pressed onto the measuring specimen surface with the standard loading and unloading profiles. The Young's modulus $E_{\mathrm{r}}(\mathrm{GPa})$ was obtained with the initial unloading stiffness $S$. Stiffness contact is then related to the reduced Young's modulus $E_{\mathrm{r}}$ according to Eq. (1):

$$
E_{\mathrm{r}}=\frac{\sqrt{\pi}}{2 \beta} \frac{S}{A_{\mathrm{c}}},
$$

where $\beta$ is a constant which depends on the geometry of used Cube Corner indenter. $A_{\mathrm{c}}$ is the contact area of indentation. In the nanoindentation test, the quasistatic nanoindentation was performed by 16 punches at the selected microstructure site (Fig. 8), while the measured area is limited by the area of $75 \times 75 \mu^{2}$. 
Table 4. Evaluated texture parameters of machined surfaces

\begin{tabular}{|c|c|c|}
\hline Parameter & Unit & Parameter description \\
\hline \multicolumn{3}{|c|}{ 2D amplitude (altitudinal) parameters of roughness (EN ISO 4287) } \\
\hline$R a$ & \multirow{5}{*}{$(\mu \mathrm{m})$} & Arithmetic mean deviation of the roughness profile \\
\hline$R q$ & & Root-mean-square deviation of the roughness profile \\
\hline$R z$ & & Maximum height of roughness profile \\
\hline$R t$ & & Total height of roughness profile \\
\hline \multirow[t]{2}{*}{$R 3 z$} & & Mean of the third maximum height of the roughness profile \\
\hline & \multicolumn{2}{|c|}{ 2D length parameters of roughness (EN ISO 4287) } \\
\hline \multirow[t]{2}{*}{$R S m$} & $(\mathrm{~mm})$ & Mean width of the roughness profile elements \\
\hline & \multicolumn{2}{|c|}{ 2D shape parameters of roughness (EN ISO 4287) } \\
\hline \multirow{3}{*}{$\begin{array}{l}R d q \\
R d a\end{array}$} & $\left({ }^{\circ}\right)$ & The root-mean-square slope of the roughness profile \\
\hline & \multirow{2}{*}{\multicolumn{2}{|c|}{ Material ratio (EN ISO 4287) }} \\
\hline & & \\
\hline \multirow[t]{2}{*}{$R m r$} & $(\%)$ & The relative material ratio of the roughness profile \\
\hline & \multicolumn{2}{|c|}{ 3D amplitude (altitudinal) parameters of roughness (EUR 15178N) } \\
\hline$S a$ & \multirow{4}{*}{$(\mu \mathrm{m})$} & Arithmetic mean deviation \\
\hline$S q$ & & Root mean square mean deviation \\
\hline$S z$ & & Ten point height \\
\hline$S t$ & & Total height \\
\hline
\end{tabular}

Standard trapezoid with a maximum of $5000 \mu \mathrm{N}$ and a pushing time of 4 seconds was used as load curve, which is also mentioned above. All the measured values of nano-hardness $H$ ( $\mathrm{GPa})$ for the same testing material also can be seen in Fig. 9.

\subsection{Analysis of machined surfaces texture}

Surface texture was measured by the coherence correlation interferometer Talysurf CCI Lite and evaluated using TalyMap Platinum software. The basic length cut-off $\lambda_{\mathrm{c}}=0.8 \mathrm{~mm}$ and the evaluated length $l n=4 \mathrm{~mm}$ were chosen in accordance with the EN ISO 4288 standard at measuring 2D surface texture parameters. Selected 2D texture parameters of machined surfaces were obtained from the resulting crosssectional profile as the mean value of 1024 individual profiles. In the case of $3 \mathrm{D}$ surface texture evaluation, an area of $0.8 \times 0.8 \mathrm{~mm}^{2}$ was analyzed. The evaluated parameters are listed in Table 4.

As a result of the use of various technological operations, unevenness was created on the surface of machine parts. Technological factors that cause surface roughness simultaneously affect the properties of the surface layer of the component material (strengthening, residual stresses, microcracks, structural defects, etc.). This part of the experiment was focused on the influence of selected machining parameters $\left(v_{\mathrm{c}}, a_{\mathrm{p}}, f\right)$ on selected texture characteristics of the surface and their quantitative evaluation.

\section{Results and discussion}

The average size of the original austenitic grain (grains after the last austenitizing) was about $50 \mu \mathrm{m}$, as seen in Fig. 1. The evaluated microstructure corresponds to the condition after quenching and hightemperature tempering of the coarse-grained $\mathrm{Cr}-\mathrm{Ni}$ -Mo-V steels.

The subsurface areas of machined surfaces showed signs of plastic deformation of the microstructure that was noticeable up to the depth of approximately $5 \mu \mathrm{m}$ and was viewed microscopically up to the depth of about $25 \mu \mathrm{m}$, as seen in Fig. 2. Measuring of nanohardness course in cross-section showed a more detailed view on deformation areas and their depths.

In steels, two distinct morphologies of martensite are seen: lath and plate martensite. Lath martensite was formed in low and medium carbon steels with low content of alloying elements. Medium carbon steels have mixed lath as well as plate martensites complex structure. Lath martensite structure shows the smallest dimensions, which significantly affects the 


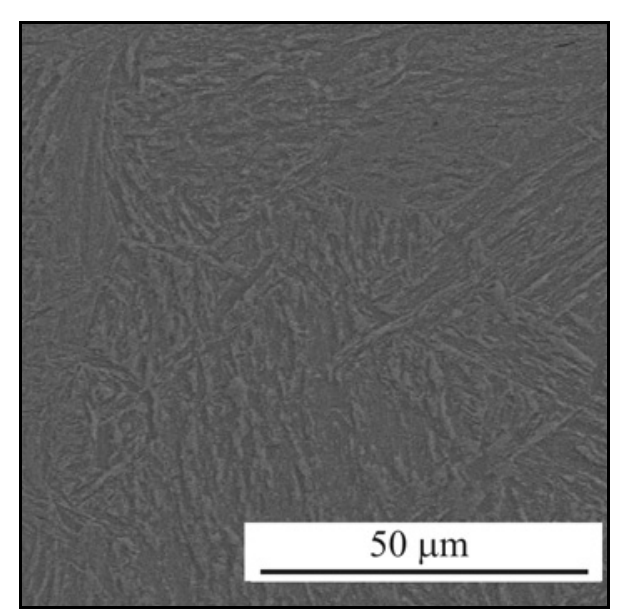

Fig. 1. The microstructure of OCHN3MFA bulk material, etch. Nital.

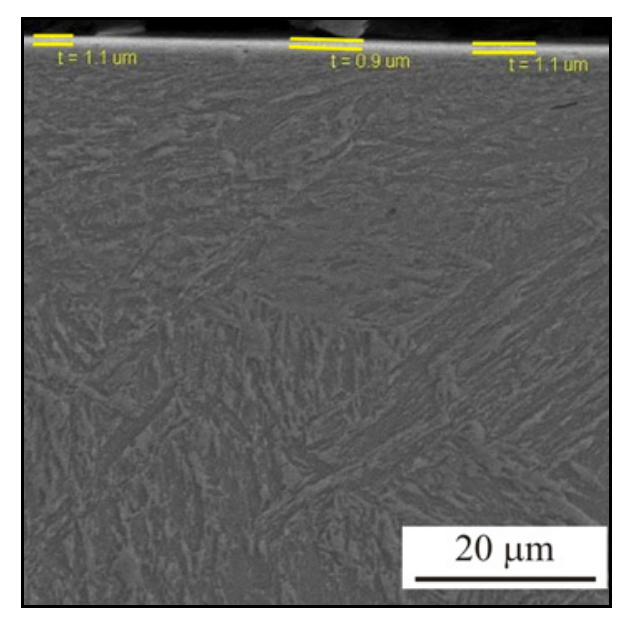

Fig. 2. The microstructure of OCHN3MFA surface layers known as Bielby, etch. Nital.

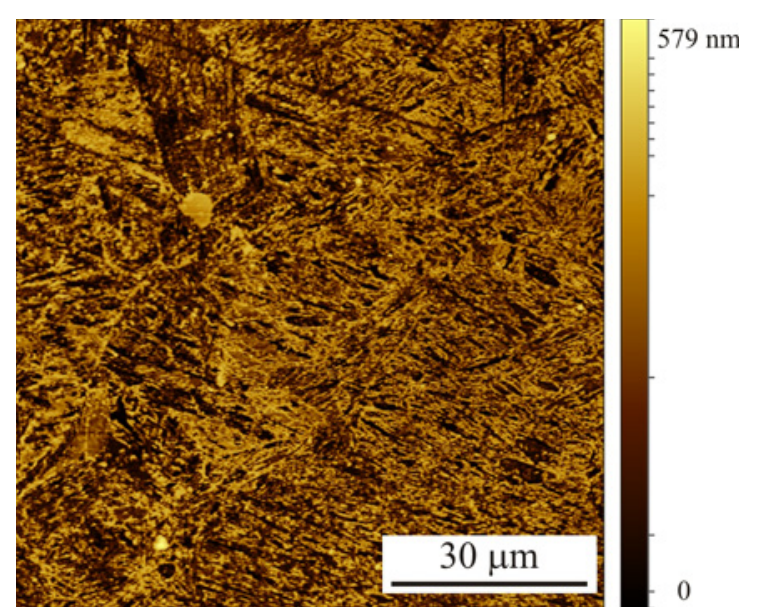

Fig. 3. AFM topography image $90 \times 90 \mu \mathrm{m}^{2}$ of OCHN3MFA bulk material, etch. Nital. Lath martensite prevails.

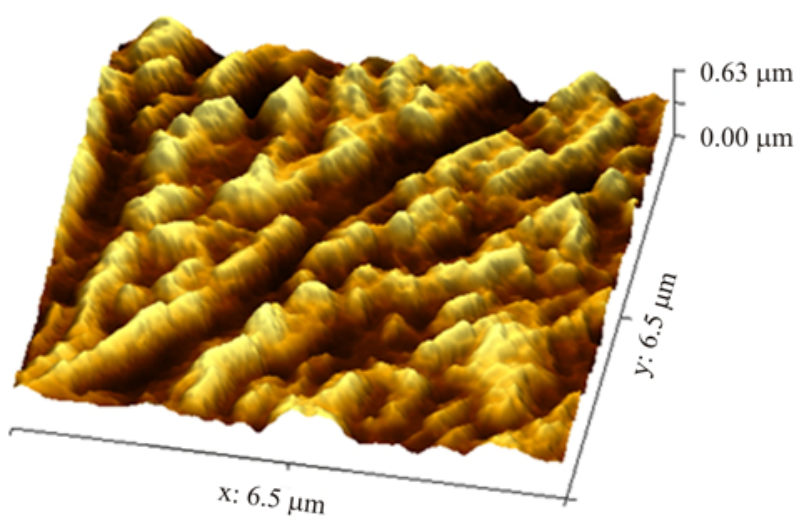

Fig. 4. 3D topography of $6.5 \times 6.5 \mu \mathrm{m}^{2}-$ the topography of martensite laths.

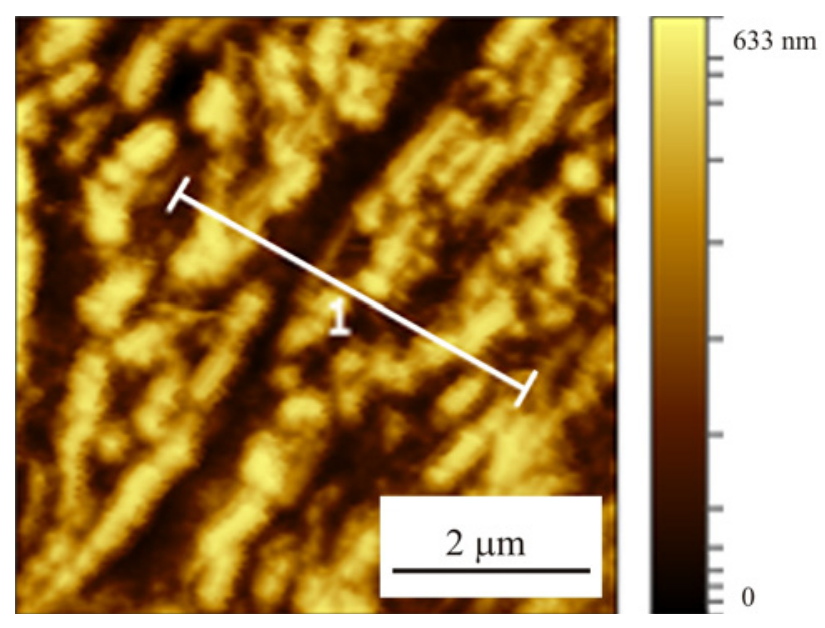

Fig. 5. AFM image with the highlighted location for measuring the laths width (white line).

strengthening mechanism. One of the parameters that represent the size of the lath structure is the lath width. Atomic force microscopy (AFM) was used to investigate the martensite structure, instead of SEM or TEM. Advantages of AFM include rapid sample preparation and obtaining the sample's 3D surface topography.

Figure 3 shows a $90 \times 90 \mu \mathrm{m}^{2}$ topography image of sample preparation through standard metallographic methods. As can be seen, the lath martensite structure prevails. Figure 4 shows the 3D topography of focused lath martensite structures.

The place, where the laths width was measured is shown in Fig. 5 by a white line and the profile of this line area is in Fig. 6.

Table 5 shows the results from measuring the width of martensite laths. The results show that the width varies from 1.206 to $1.351 \mu \mathrm{m}$.

Force load was measured in three axes by Kistler 9257B dynamometer equipped with 5070A eight- 


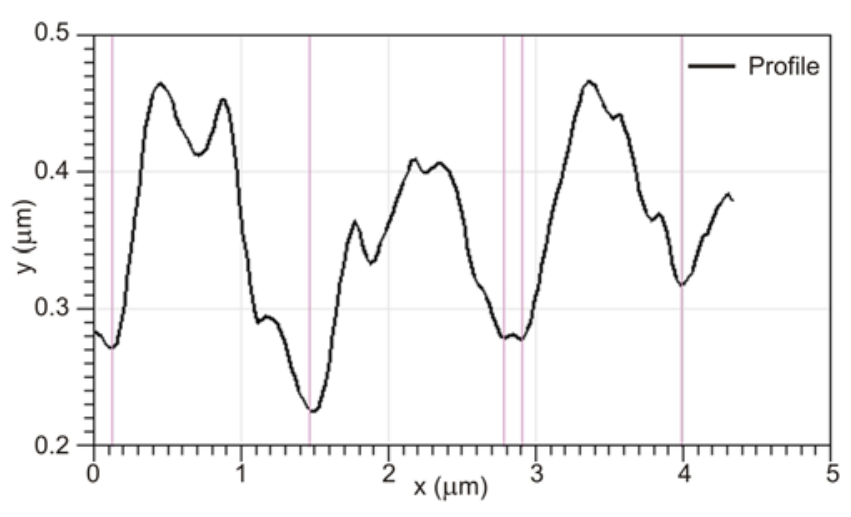

Fig. 6. Profile of the martensite laths.

Table 5. The width of the martensite laths

\begin{tabular}{cc}
\hline No. of lath & Width $(\mu \mathrm{m})$ \\
\hline 1 & 1.351 \\
2 & 1.289 \\
3 & 1.206 \\
\hline
\end{tabular}

-channel amplifier, while software Dynoware was used for data processing. Monitored parameters included the values of cutting forces during longitudinal turning.

The lowest values of force load were achieved when feed rate $f_{1}$ was set up, while the highest ones with feed rate $f_{3}$. These results were expected as setting a higher feed rate means higher energy intensity and higher force load. The average values of cutting forces $F_{\mathrm{c}}$ are shown in Table 6 and Fig. 7.

Nanoindentation of surface layers formed after machining represents the next aspect of the experiments. The subject of nanoindentation included surface layers of three samples machined at the feed rates of $f_{1}=0.22 \mathrm{~mm} \mathrm{rev}^{-1}, f_{2}=0.34 \mathrm{~mm} \mathrm{rev}^{-1}$, and $f_{3}=$ $0.41 \mathrm{~mm} \mathrm{rev}^{-1}$. The analyzed microstructure of surface layers with plastic deformation after machining is shown in Fig. 2. It displays SPM (Scanning Probe Microscopy) image (gradient channel) of the measured area with the dimension of $75 \times 75 \mu^{2}$ as shown in Fig. 8. All measuring locations are then marked with green spots. All these can also be seen in Fig. 8 .

Hysitron TI-950 measuring device and its quasistatic nanoindentation method were used to deter-

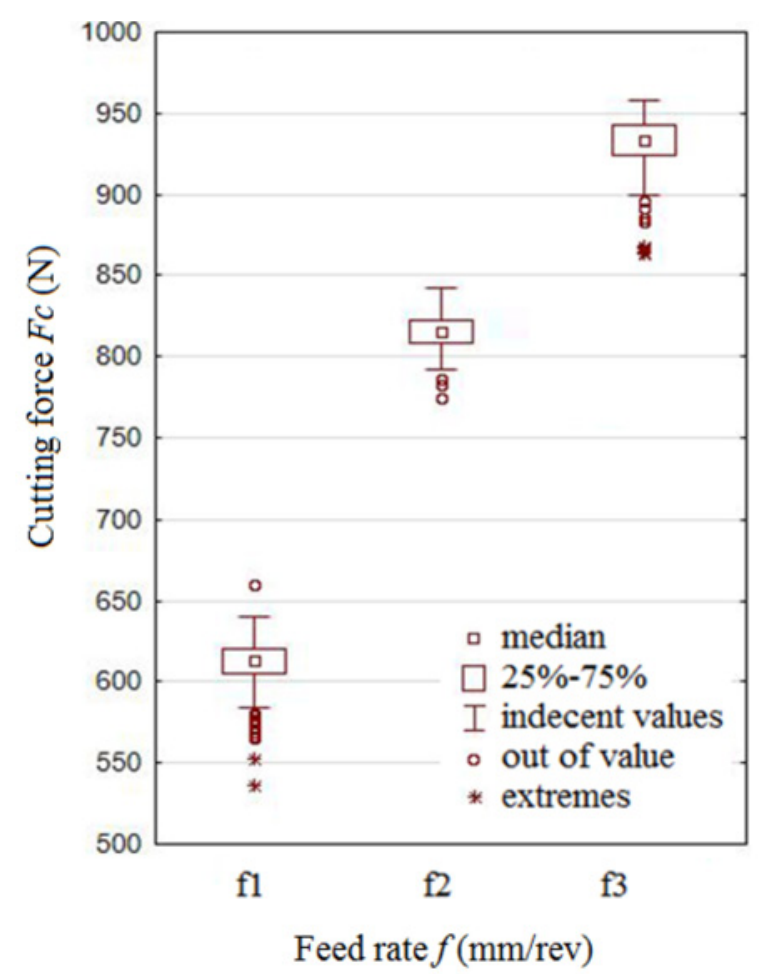

Fig. 7. Reached values of $F_{\mathrm{c}}$ cutting force.

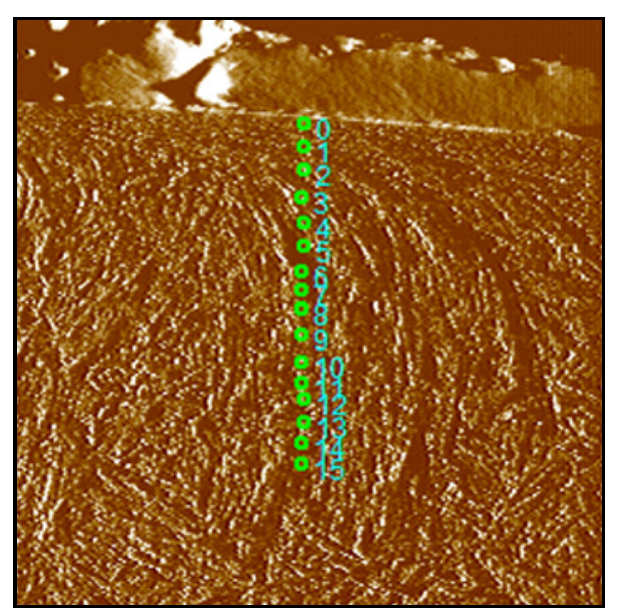

Fig. 8. SPM image of surface layer $\left(f_{3}=0.41 \mathrm{~mm} \mathrm{rev}^{-1}\right.$, channel: Gradient, area $\left.75 \times 75 \mu \mathrm{m}^{2}\right)$ and the measurement location.

mine nano-hardness $H$ in every selected spot. Load parameters are the same for every measurement. Trape-

Table 6 . Reached average values of cutting force $F_{\mathrm{c}}$

\begin{tabular}{lccc}
\hline Feed rate & $f_{1}=0.22 \mathrm{~mm} \mathrm{rev}^{-1}$ & $f_{2}=0.34 \mathrm{~mm} \mathrm{rev}^{-1}$ & $f_{3}=0.41 \mathrm{~mm} \mathrm{rev}^{-1}$ \\
\hline Cutting force $F_{\mathrm{c}}$ & $770 \mathrm{~N}$ & $966 \mathrm{~N}$ & $1075 \mathrm{~N}$ \\
\hline
\end{tabular}


Ta ble 7 . Measured values of $2 \mathrm{D}$ amplitude (altitudinal) parameters of roughness

\begin{tabular}{|c|c|c|c|c|}
\hline \multirow{2}{*}{ Parameter } & \multirow{2}{*}{ Unit } & \multicolumn{3}{|c|}{ Measured values } \\
\hline & & $\mathrm{A} 1$ & A3 & A4 \\
\hline$R a$ & \multirow{4}{*}{$(\mu \mathrm{m})$} & $1.641 \pm 0.119$ & $2.383 \pm 0.136$ & $1.933 \pm 0.076$ \\
\hline$R q$ & & $1.927 \pm 0.110$ & $2.807 \pm 0.159$ & $2.386 \pm 0.070$ \\
\hline$R z$ & & $7.061 \pm 0.025$ & $10.970 \pm 0.919$ & $10.840 \pm 0.198$ \\
\hline$R t$ & & $7.154 \pm 0.047$ & $11.330 \pm 0.764$ & $11.840 \pm 0.382$ \\
\hline
\end{tabular}

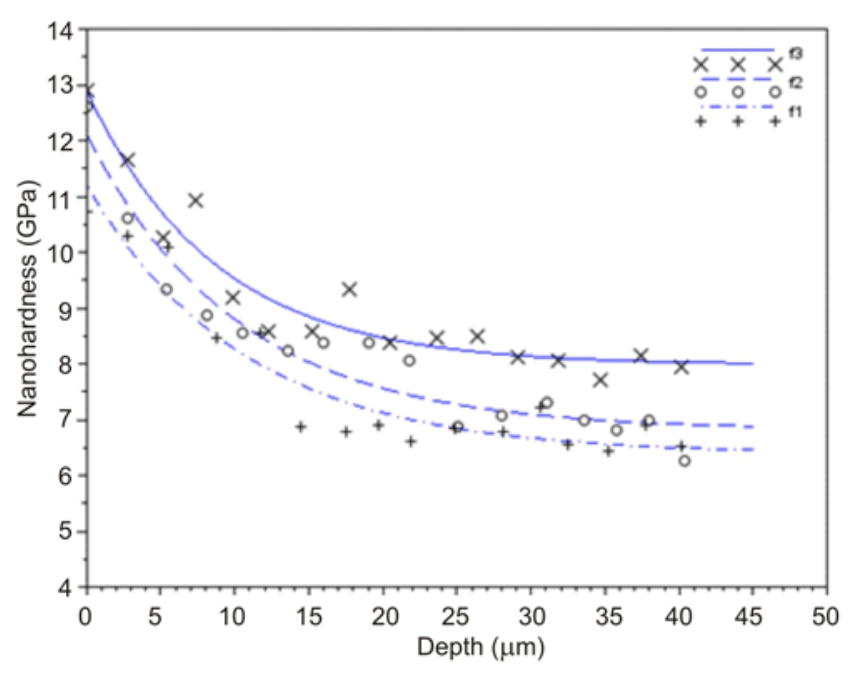

Fig. 9. Hardness course of surface layers for the feed rates $f_{1}=0.22 \mathrm{~mm} \mathrm{rev}^{-1}, f_{2}=0.34 \mathrm{~mm} \mathrm{rev}^{-1}$, and $f_{3}=$ $0.41 \mathrm{~mm} \mathrm{rev}^{-1}$.

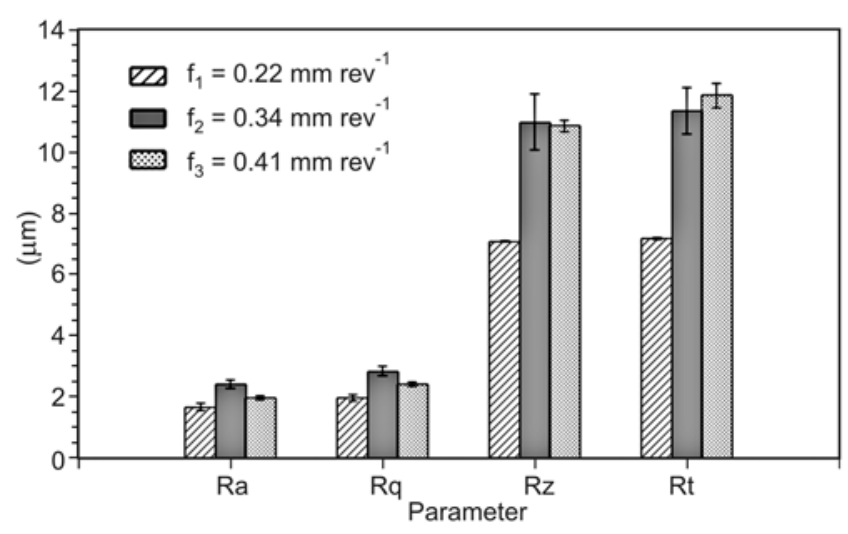

Fig. 10. 2D amplitude (altitudinal) roughness parameters.

zoid load curve with the maximum load of $F=$ $5000 \mu \mathrm{N}$ and the holding time $t=4 \mathrm{~s}$ was used. Higher indentation load was chosen due to the higher hardness of the experimental material. Curves of hardness courses are seen in Fig. 9 and are created by fitting experimental data through nonlinear regression with the use of an exponential function.

All three courses were characterized by initial high rate hardness decreasing in part to the depth of about $15 \mu \mathrm{m}$, followed by soft degressivity in hardness values. Also, hardness values depend on feed rates. Sample with a higher feed rate has its surface layer with the highest hardness values. These values decrease with the decreasing feed rate (Fig. 9).

In view of roughness parameters, the following results were acquired: From 2D amplitude (altitudinal) roughness parameters, the parameters $R a, R q, R z$, and $R t$ were evaluated. Comparison of selected roughness parameters, depending on the selected machining parameters (feed value $f$ ), is documented in Fig. 10 . Numerical values are shown in Table 7 .

In the case of the $R a$ parameter, it is necessary to realize that the height characteristics of $R a$ provides only the mean value of the distance of the individual points 'coordinates' within the examined surface from the median line of the profile. It is only a statistical value, a control parameter. For this reason, $R a$ does not need to be effective in all cases of assessing the roughness of the surface profile. Arithmetic mean deviation of the $R a$ roughness profile cannot give the impression of how the surface created by technological operation looks like. This is a fundamental characteristic for describing the microgeometry of the surface; it is widely used and defended because the surface roughness assessment according to $R a$ is relatively inexpensive. The obtained values show relatively considerable accuracy in repeated measurements. The averaging nature of $R a$ makes it a stable parameter which is not affected by accidental or apparent peaks or scratches. From Fig. 10 and the measured values in Table 7, it is apparent that the $R a$ parameter had the lowest value at $f_{1}=0.22 \mathrm{~mm} \mathrm{rev}{ }^{-1}$ feed rate, with an increase in the feed rate to $f_{2}=0.34 \mathrm{~mm} \mathrm{rev}^{-1}$, there was an increase in $R a$, but at the highest feed rate $f_{3}=$ $0.41 \mathrm{~mm} \mathrm{rev}^{-1}$ the $R a$ value decreased.

$R q$ parameter has a highlighting effect on single or random peaks and valleys. For statistical processing, $R q$ values are more significant than $R a$. This parameter is not widely used in general engineering. However, its ability to detect random peaks and valleys is much more useful in the optical industry. The $R q$ parameter, depending on the feed rate, reached slightly higher values than $R a$. The course of values for individual feed rates is the same as $R a$. 
Table 8. Measured values of the material ratio

\begin{tabular}{ccccc}
\hline \multirow{2}{*}{ Parameter } & Unit & \multicolumn{3}{c}{ Measured values } \\
\cline { 3 - 5 } & & A1 & A2 & A3 \\
\hline$R m r$ & $(\%)$ & $10.845 \pm 0.672$ & $1.540 \pm 0.010$ & $2.090 \pm 0.507$ \\
\hline
\end{tabular}

Table 9. Measured values of 3D amplitude (altitudinal) roughness parameters

\begin{tabular}{|c|c|c|c|c|}
\hline \multirow{2}{*}{ Parameter } & \multirow{2}{*}{ Unit } & \multicolumn{3}{|c|}{ Measured values } \\
\hline & & $\mathrm{A} 1$ & $\mathrm{~A} 2$ & A3 \\
\hline$S a$ & \multirow{4}{*}{$(\mu \mathrm{m})$} & $1.699 \pm 0.124$ & $2.611 \pm 0.338$ & $2.194 \pm 0.186$ \\
\hline$S q$ & & $2.004 \pm 0.057$ & $3.072 \pm 0.322$ & $2.670 \pm 0.148$ \\
\hline$S z$ & & $12.786 \pm 7.813$ & $12.115 \pm 0.827$ & $11.625 \pm 0.078$ \\
\hline St & & $13.303 \pm 8.467$ & $13.750 \pm 2.673$ & $12.860 \pm 0.750$ \\
\hline
\end{tabular}

The maximum height of the $R z$ roughness profile is a bit more stable than the total height of $R t$ roughness profile, due to averaging over several basic lengths. $R z$ is the alternative to $R t$ as a control parameter. The $R z$ characteristic is suitable for evaluation of rough surfaces. In contact sliding surfaces, it expresses the probability that the peaks of the profile will penetrate the oil film. From Fig. 10 and the values in Table 7, it is evident that at $f_{1}=0.22 \mathrm{~mm} \mathrm{rev}^{-1}, R z=7.061 \mu \mathrm{m}$ was achieved. Increasing the feed rate to $f_{2}$ increased the profile height by about $3 \mu \mathrm{m}$. This increase remained almost constant at the highest $f_{3}$ feed rate.

The maximum distance between the peak and the valley of the profile on the evaluated length $(l n)$ is represented by the total height of the $R t$ roughness profile. This is a peak parameter; therefore, it is loaded with a large scatter of values and may be unstable. It shows extreme boundaries of the profile, but it may not be credible - a single peak or valley affects the value of $R t$. It is particularly used as a control parameter especially in applications where components are subject to high stress. Individual large peaks can penetrate the oil lubrication film and increase wear, abrasion, and damage to sliding surfaces. Figure 10 and the results in Table 7 show similarity in $R z$ and $R t$. There was a slight increase in $R t$ values; otherwise, the course of values for each feed rate correlates approximately with that obtained with $R z$. From the results, it can be assumed that increased feed rate increases the distance between the peaks and the valleys. Between the $f_{1}$ and $f_{2}$ feed rate, there is a sudden increase in $R z$ and $R t$ values. At higher feed rates $\left(f_{2}, f_{3}\right), R z$ and $R t$ values become stabilized, while $R z$ might eventually slightly decrease, or $R t$ slightly increase.

Transverse surface roughness profiles of the machined parts within the selected feed rates are shown in Fig. 11.
$R m r$ material ratio is a ratio expressed in percentage of material-filled length to the $l n$ evaluation length at level $c$ profile section. Although $R m r$ simulates the wear effect, it cannot normally replace the actual running-in tests. The material ratio is a fraction of the length and not of the surface area, ignoring the holes that may occur due to waviness or shape. $R m r$ refers to the unloaded profile, while the actual surface may experience plastic deformation. Qualitative evaluation of the bearing curves is usually sufficient to classify practical surface profiles with respect to their different operating loads. Level $c$ profile section was selected at $1 \mu \mathrm{m}$ under the peaks line of the profile. Values of $R m r$ material ratio are documented in Table 8 .

Feed rate $f_{1}$ provides a more bearing surface than $f_{2}$ and $f_{3}$. Material ratio $R m r$ in the case of feed rates $f_{2}$ and $f_{3}$ correlates with the roughness of the surface. That is, at a higher feed rate, the material ratio is reduced, which increases slightly again at the highest feed rate.

$3 \mathrm{D}$ analysis of the surface was performed using the parameters $S a, S q, S z$, and $S t$. Measured values are shown in Fig. 12 and Table 9.

Quantification of selected characteristics in all three dimensions can provide different data for a comprehensive description of the shape of the investigated surface. Evaluation of surface isotropy within the three-dimensional texture assessment is of particular importance for types of surfaces exhibiting little or no directional effect (no roughness direction is indicated on the surface).

Quantification of 3D parameters correlates with the evaluation of $2 \mathrm{D}$ amplitude parameters. Arithmetic mean deviation of the considered area $S a$ is similar to $R a$ in the case of a profile. Obtained values for each feed rate are also the same. Similar parameters are also obtained in the case of $S q$ parameter. Differ- 

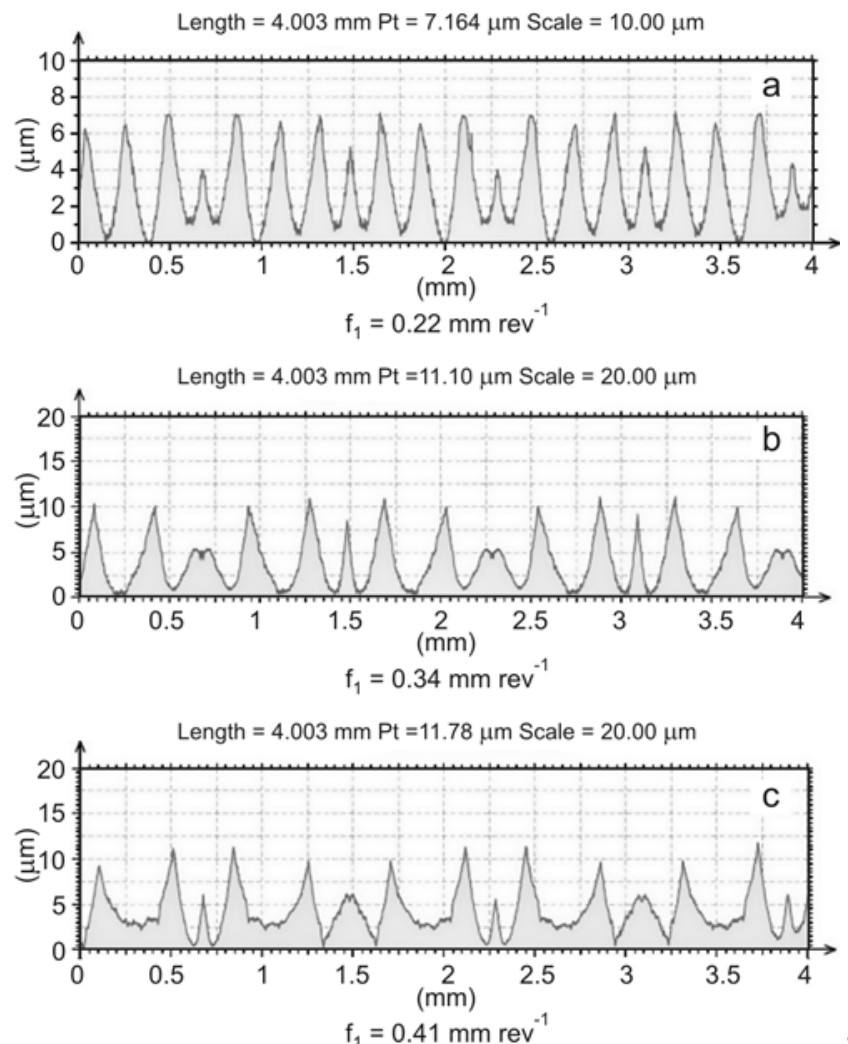

Fig. 11. Transverse profiles of surface roughness.

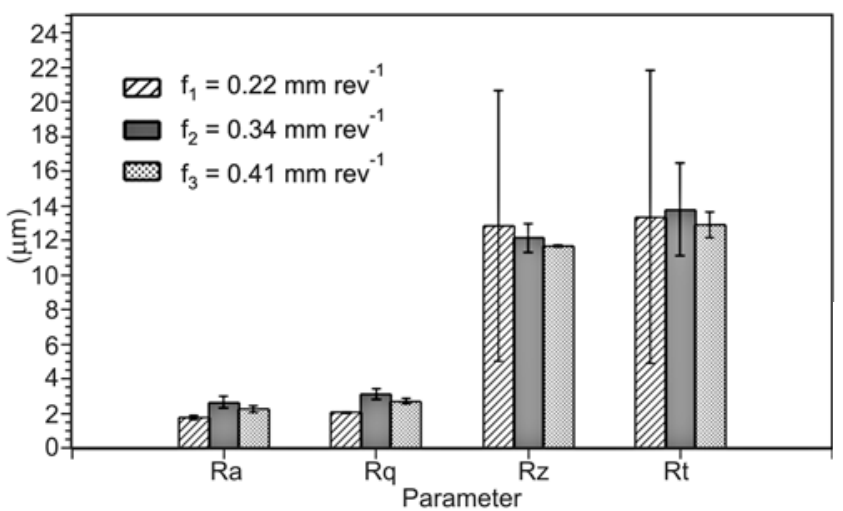

Fig. 12. 3D amplitude roughness parameters.

ent results were achieved for $S z$ parameter, while with an increase in values of feed rate $f, S z$ decreased. In the case of $S t$ parameter, there was a slight increase in value at increased feed rate from $f_{1}$ to $f_{2}$; however, feed rate $f_{3}$ signified the lowest values of $S t$. 3D topography of surfaces under selected machining conditions (feed rates) is documented in Figs. $13 \mathrm{a}-\mathrm{c}$.

\section{Conclusions}

This article analyzed the effect of selected cutting parameter values in machining of the OCHN3MFA
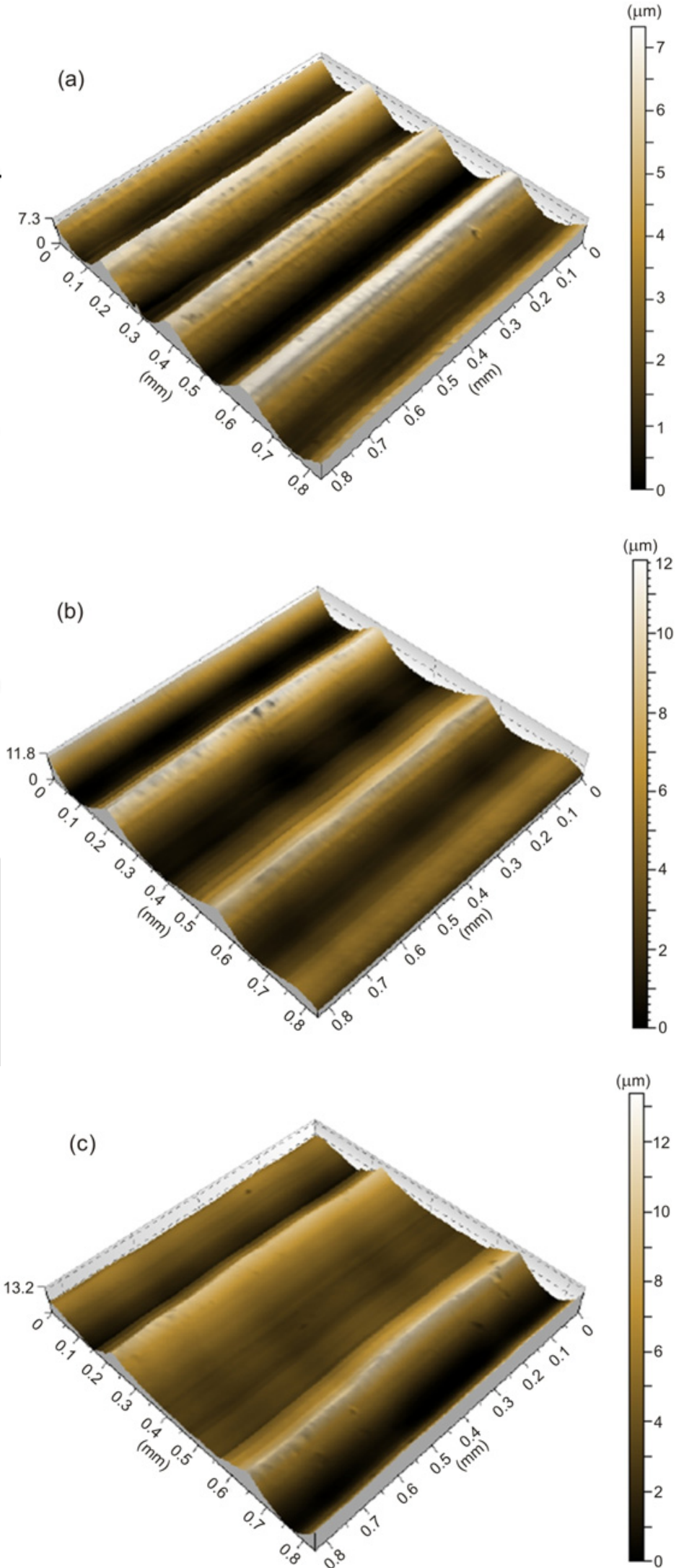

Fig. 13. 3D topography of surface at $f_{1}=0.22 \mathrm{~mm} \mathrm{rev}^{-1}$ (a), $f_{2}=0.34 \mathrm{~mm} \mathrm{rev}^{-1}$ (b), $f_{3}=0.41 \mathrm{~mm} \mathrm{rev}^{-1}$ (c). 
steel on AFM and SEM microstructural analysis, cutting forces, nano-hardness, 2D and 3D surface roughness, the material removal rate of surface layers after machining, while summarizing the obtained results as follows:

- The microstructure is slightly heterogeneous, relatively coarse-grained, and consists of high-tempered martensite and bainite, along with fine globular secondary carbides.

- Results of metallographic analysis of the cross-section of the samples showed changes in the structure of the sample's surface layer after machining.

- Obtained nanohardness values show that the hardened layer of the machined surface is well cohesive to the base material and is not mechanically damaged. In particular, the increased hardness of this layer increases the wear resistance of the surface, from which a longer lifetime can be derived.

- Results of the nanohardness (surface hardening) measurements also showed a reinforcing effect. The greatest consolidation occurred in samples that were machined at the highest feed rate.

- Increase in surface layer hardness of the machined surface is mainly determined by the mechanical load on the surface of the workpiece during machining.

- Longitudinal turning was stable at all setup feed rates while the minimum number of outlying values and extremes of cutting forces was observed.

- The used cutting tool could work at higher cutting and feed speeds.

- The highest value of $F_{\mathrm{c}}$ cutting force was achieved with $f_{3}$ feed rate, lowest with $f_{1}$ feed rate.

- Average surface roughness characteristic values of samples after machining were found to be almost the highest at $f_{2}$, as when compared with samples machined at $f_{1}$ and $f_{3}$ feed rates. Quantification of $3 \mathrm{D}$ parameters also correlates with evaluation of $2 \mathrm{D}$ amplitude parameters.

Theoretical knowledgebase obtained during the performed experiments provides direct ground for recommending further research in the area of machining of test samples with changeable cutting inserts with different geometry at maintaining the same cutting conditions. For future expansion of the evaluated integrity parameters of test samples, it might also be advisable to measure cutting tool wear and residual stresses, along with implementing a complete concept of surface integrity to complement purely functional tests.

The results of the experiment showed the options of utilization of mentioned steel for producing highly stressed parts of weapons and ammunition.

\section{Acknowledgements}

This work was supported by the Slovak Research and Development Agency under contract No. APVV-15-0710 and by the BUT, Faculty of Mechanical Engineering, Brno, Specific Research 2016, within the grant scheme of "Research of Modern Production Technologies for Specific Applications", FSI-S-16-3717, and also by a Research Project for the Development of Technologies, Design of Firearms, Ammunition, Instrumentation, Engineering of Materials and Military Infrastructure "VÝZBROJ (DZRO K201)".

\section{References}

[1] Jamil, W. N. M., Aripin, M. A., Sajuri, Z., Abdullah, S., Omar, M. Z., Abdullah, M. F., Zamri, W. F. H.: International Journal of Automotive and Mechanical Engineering, 13, 2016, p. 3742. doi:10.15282/ijame.13.3.2016.16.0306

[2] Fabre, D., Bonnet, C., Rech, J., Mabrouki, T.: CIRP Journal of Manufacturing Science and Technology, 18, 2017, p. 120. doi:10.1016/j.procir.2017.03.181

[3] He, C. L., Zong, W. J., Xue, C. X., Sun, T.: International Journal of Machine Tools and Manufacture, 134, 2018, p. 42. doi:10.1016/i.ijmachtools.2018.07.004

[4] Dias, T., Paulo, N., Queijo, L., Lopes, H. R., César, M. B., Ribeiro, J. E.: Lecture Notes in Electrical Engineering, 402, 2017, p. 583. doi:10.1007/978-3-319-43671-5_49

[5] Tomanik, E., Mansori, M. E., Souza, R., Profito, F.: Tribology International, 120, 2018, p. 550. doi:10.1016/i.triboint.2018.12.014

[6] Baday, Ş., Başak, H., Güral, A.: Kovove Mater., 54, 2016, p. 315. doi: $10.4149 / \mathrm{km} 20165315$

[7] Junki, J., Thouless, M. D., Barber, J. R.: Journal of the Mechanics and Physics of Solids, 118, 2018, p. 365. doi:10.1016/i.jmps.2018.06.005

[8] Dhar, S., Kamruzzaman, M., Mahiuddin, A.: Journal of Materials Processing Technology, 172, 2006, p. 299. doi:10.1016/j.jmatprotec.2005.09.022

[9] Moorthy, V., Shaw, B. A.: Wear, 297, 2013, p. 878. doi:10.1016/i.wear.2012.11.001

[10] Majernik, J., Gaspar, S., Gryc, K., Socha, L.: Manufacturing Technology, 2018, 18, p. 439. doi:10.21062/ujep/118.2018/a/1213-2489/MT/18/3/ 439

[11] Sun, C., Deng, Y., Lan, D., Xiu, S.: Procedia CIRP, 71, 2018, p. 364. doi:10.1016/j.procir.2018.05.042

[12] Brinksmeier, E., Klocke, F., Lucca, D. A., Sölter, J., Meyer, D.: Procedia CIRP, 13, 2014, p. 429. doi:10.1016/j.procir.2014.04.073

[13] Safi, M. S., Givi, M. K. B.: Metal Science and Heat Treatment, 56, 2014, p. 78. doi:10.1007/s11041-014-9707-z

[14] Rashid, B. W., Goel, S., Davim, J. P., Joshi, S. N.: International Journal of Advanced Manufacturing Technology, 82, 2016, p. 451. doi:10.1007/s00170-015-7337-2

[15] Luo, L., Huang, Y., Weng, S., Zhen, X. F.: Materials and Design, 105, 2016, p. 240. doi:10.1016/j.matdes.2016.05.058

[16] Llaneza, V., Belzunce, F. J.: Applied Surface Science, 356, 2015, p. 475. doi:10.1016/j.apsusc.2015.08.110

[17] Guifang, S., Rui, Z., Jinzhong, L., Jyotirmoy, M.: Acta Materialia, 84, 2015, p. 172. doi:10.1016/j.actamat.2014.09.028 
[18] Segurado, E., Belzunce, F. J., Fernández, P. I.: International Journal of Advanced Manufacturing Technology, 96, 2018, p. 1225. doi:10.1007/s00170-017-1533-1
[19] Saadatbakhsh, M. H., Hadi, I., Sadeghi, M. H., Farshi, S. S.: International Journal of Advanced Manufacturing Technology, 93, 2017, p. 4063. doi:10.1007/s00170-017-0782-3 